\title{
Ubuntu as a Moral Theory: Reply to Four Critics
}

\author{
Thaddeus Metz \\ University of the Witwatersrand \\ $<$ Thaddeus.Metz@wits.ac.za>
}

\begin{abstract}
In this article, I respond to questions about, and criticisms of, my article "Toward an African Moral Theory" that have been put forth by Allen Wood, Mogobe Ramose, Douglas Farland and Jason van Niekerk. The major topics I address include: what bearing the objectivity of moral value should have on cross-cultural moral differences between Africans and Westerners; whether a harmonious relationship is a good candidate for having final moral value; whether consequentialism exhausts the proper way to respond to the value of a harmonious relationship; what makes a moral theory count as "African"; how the existing literature on African ethics relates to the aim of analytically developing and defending a single foundational moral principle; whether the intuitions I appeal to ground an African moral theory are pro tanto rightmakers or general moral truths; whether the moral theory I defend can capture pro tanto rightness; and whether the best interpretation of African ethics is self-regarding (deeming the only basic moral reason for action to be that it would develop one's own valuable human nature) or other-regarding (holding that a certain kind of harmonious relationship between individuals could ground a basic moral reason for action).
\end{abstract}

By way of introduction I would like to thank heartily Professor Allen Wood, Professor Mogobe Ramose, Dr Douglas Farland and Mr Jason van Niekerk for taking the time to think about "Toward an African Moral Theory" (2007a) and for sharing their thoughts with me and others. It is an honour and pleasure to have my work analyzed by such insightful critics as well as to have the opportunity to share my reactions to their criticisms and suggestions. I have learned a great deal from this symposium, including about how much more I have to learn.

\section{Objective and Final Value: Reply to Wood}

Allen Wood's article discusses a number of important issues in meta- and normative ethical theory, e.g., the evidence for the objectivity of moral reasons, the evidence against relativism, the explanation of differences in cultures' moral beliefs, an account of why such differences should give one reason to question one's moral views, an analysis of when one culture has reason to believe it is correct, the value of harmony, the best way to capture a normative injunction with regard to harmony, and the expectations one should have of a normative ethical theory. I am struck by the elegance with which these different topics in moral philosophy are unified in Wood's article. He brings out certain logical relationships among them, and analyses them with plausibility and depth. I do not have space to take up all of Wood's insights and suggestions here, and so focus on the three on which I have the most to say and am most con- 
cerned to question: his rationale for taking the views of other cultures seriously, his suggestion that the value of harmony is merely instrumental, and his proposal to reject a teleological conception of how to respond to the value of harmony (supposing it had final, and not merely instrumental, value).

Wood argues that moral goods, norms and reasons, which I will call simply "morality," are objective (or that we have no choice but to believe that they are) and argues that, for this reason, it is worth taking seriously differences in moral beliefs between Western and African societies. Differences in moral judgment (at least when they are a product of careful, even-handed reflection) can give one epistemic reason to question one's own moral views if and only if it is possible for one's views to be mistaken, and it is possible for one's views to be mistaken if and only if morality is objective, i.e., obtains independently of being the object of one's propositional attitudes. If, in contrast, morality were subjective, in the sense of being constituted by one's mind (or the minds of a majority in one's society), then the fact that minds in another culture have a different perspective would give one's own mind no reason to change, for there would be nothing independent of one's mind that one is failing to apprehend.

Although Wood is correct - and is so by definition - that fallibilism is the partner of mind-independence and not of mind-dependence (or, more carefully, its relativist variants), I think he concludes too quickly that mind-independence is sufficient to think that cross-cultural differences in moral beliefs can give one reason to doubt one's own moral views. The problem is that, even if morality were objective in the sense of being mind-independent, it would not follow that morality is universal in scope, which condition is required for differences of opinion across cultures to give one epistemic reason to question the views of one's own culture. It is logically possible for morality to obtain independently of the minds of a particular society, and yet for this morality to apply only to this society, such that another society's differences in moral view would be irrelevant to appraising one's own. Let me first map out how this is conceptually coherent, provide reason to be concerned that the possibility might be actual, point out that Wood has given us no explicit reason to think it is not actual, but then conclude that Wood might have implicitly given us some reasons for doubting that it is actual.

Normally, the following pairs of distinctions are found together: mind-independence and universal scope, on the one hand, and mind-dependence and relative scope, on the other. Usually when a fact obtains independently of people's propositional attitudes, the fact applies to all people. For instance, the reason that water is $\mathrm{H}_{2} \mathrm{O}$ for everyone (regardless of whether they recognize it or not) is partly explained by there being a mind-independent fact, i.e., a fact about the way the world is apart from our apprehension of it, that water is $\mathrm{H}_{2} \mathrm{O}$. In contrast, typically when a fact does not apply to all people, a large part of the reason is that it logically depends on people's propositional attitudes. It is rude to belch at the table for only some societies and not all of them principally because this fact is constituted by a society's beliefs about rudeness; if a society does not believe it is rude to belch at the table, then it is not rude and is not simply for that reason.

However, Immanuel Kant most strikingly demonstrated to us that we need to consider the possibility that these distinctions can come apart. In particular, Kant's entire philosophical system is, in essence, a matter of advancing claims about metaphysics, ethics and aesthetics that are mind-dependent but universal in scope. For Kant, certain claims about the world are constituted by the rational mind, and yet these claims are "true for all persons" regardless of whether they recognize them or not, because all 
persons share the same rational mind. Thomas Hobbes may also be read as making a similar (albeit more empirical and contingent) point with regard to morality. For him, moral rules (the "laws of nature") are the same for everyone since they are simply what are likely to conduce to long-term desire satisfaction, where everyone has more or less the same strongest desires, e.g., to stay alive.

Less often recognized, but no less coherent, is the possibility that certain facts obtain independently of anyone's mind but do not apply to everyone. Consider the views of some Jews that there are certain moral obligations that apply only to them, and not to gentiles, where these moral obligations are not constituted by the propositional attitudes of any human beings. One might reply that, on this view, the obligations are still constituted by God's mind, even if not ours. Fair enough, but my point is that this need not be so.

To see why not, recall discussion in the literature of "moral twin earth" (Horgan and Timmons, 1990-91). Moral twin earth is like earth in every respect, except that when we on earth use the term "morality" to refer, then, by virtue of certain causal processes (and not the mere descriptive content of the term), we pick out deontological behaviour, whereas those on moral twin earth denote consequentialist behaviour. The moral facts would be mind-independent on both planets. There would be a fact of the matter that obtains independently of anyone's propositional attitudes about the nature of the property picked out by the term "morality." People on both planets would have to learn over time about the essence (loosely construed) of the kind of interaction they have referred to with "morality"; it would not be a function merely of the definition of the term or of what people on each planet respectively believes about morality. However, what morality is would not be universal, i.e., would not be the same for both planets. Morality would be deontological on one and consequentialist on the other, and if people on both planets were to meet, they would talk past one another if they spoke of "morality." What would appear to be a moral disagreement between people on the planets would instead be a mere difference, since the meaning of their terms would not co-refer and would instead be fixed by the different natures of the "moral" stuff on their respective planets.

It is natural, of course, to point out that the cross-cultural moral differences we face are not between different planets, but rather different societies on the same planet. However, my concern is that, particularly in light of the apparent existence of substantial differences in moral views, sub-Saharan Africa and the modern West might be akin to two different planets when it comes to the referents of the term "morality." It is possible that Africans denote one sort of property with "morality," namely, a certain kind of communal relationship (if the normative ethical theory I have proposed is roughly correct), and that Westerners pick out another property, probably respect for the dignity of an individual's agency.

I am not saying that is indeed the case. Instead, I am making two points, one being that Westerns and Africans will have epistemic reason to question their own views in light of differences between them only if it is not the case. That is, in order for cross-cultural differences in moral beliefs to give one culture a reason to suspect that their views are mistaken, both cultures have to be co-referring with the term "morality" (and similar terms). Moral facts must be not only mind-independent but also universal in scope, in order for moral differences to give us epistemic pause.

My second point is that Wood has not provided any express reason to think that morality is indeed universal in scope, i.e., that both societies indeed co-refer with "moral- 
ity" such that it would be reasonable to think, in Wood's terms, that each has "hold of part of the objective truth." Wood has provided serious reason to think that morality is mind-independent, or that we must think so. He claims that acting and believing for good reasons, which we cannot help doing unless we lobotomize ourselves, is a matter of acting in light of what one takes to non-arbitrary and hence mind-independent facts (or at least facts that are independent of contingent or non-rational mental states). I worry that the case of etiquette is a counterexample to this strong claim, but no matter. Even if Wood were correct, he would not have shown that acting and believing for good reasons is a matter of acting in light of what one takes to be universal facts; for moral twin earth seems to be a coherent thought experiment, i.e., one can be a rational deliberator and chooser even if one thinks that the mind-independent reasons one is appealing to do not apply to all rational creatures.

If I am correct, then, in order for the differences between Westerners and Africans to give each of them reason to question their views, we need some reason to believe that morality is cross-cultural in scope (even if we grant that it is mind-independent), in which case it would be reasonable to think that each culture had grasped only part of the universal truth and should listen to the other for correction. Now, what would count as evidence that morality is indeed universal in scope? One good piece of evidence would be consensus. If minds tended to converge in judgment on a subject matter, a promising explanation of that fact would be that minds would be tracking a mind-independent fact that applies to all minds. Why does everyone agree that there is a moon? There is a mind-independent fact of the matter that there is one, which fact obtains with respect to all minds. If everyone were, similarly, to agree about morality, that, too, would be strong evidence that it is both mind-independent and universal in scope.

Hence, I am suggesting that Wood has an additional reason to engage in cross-cultural comparison and contrast of moral views. He does it because he thinks he has shown that morality is mind-independent (and perhaps universal), which means that we are fallible and could benefit from the correction of other societies. I am suggesting, as well, that we should do it because it could help us establish whether morality is universal or not. If the differences turned out to be deep-seated and rife, that would be some evidence that we are in a position akin to moral twin earth. If, in contrast, there turned out to be fewer differences in moral beliefs between Africans and Westerners than there might appear to be, then we would have reason to think that morality is universal and, hence, that we have reason to take seriously what differences remain, with the aim of correcting our partial and skewed apprehension of morality.

Now, one way of reading Wood's "armchair moral anthropology" is providing reason to think that the differences in moral beliefs between Westerners and Africans are by and large superficial. Wood suggests that the major reason why Africans have tended to focus on the value of what I call "harmony," i.e., roughly, the combination of sharing a sense of identity and acting for one another's sake, is that it has been "vital" for the survival of their societies. In small-scale societies with little economic surplus, Wood suggests that harmony has been particularly useful for avoiding conflict of a sort that would threaten lives and well-being. The West, in contrast, has been able to secure these without harmony and for that reason values it less. The moral differences here are, on one interpretation, not fundamental: both societies ultimately value life and well-being for their own sake, with African societies valuing harmony merely as a 
means to them and Western ones not, as is quite appropriate given their different socio-economic circumstances.

I have a mixed reaction to this appraisal of the import of cross-cultural differences between Africans and Westerners. ${ }^{1}$ On the one hand, I reject the arguments for relativism and find many of the objections to it convincing; for instance, Wood's points about fallibilism and tolerance making most sense on a non-relativist ethic are, I think, completely sound. So, I would like it to turn out, with James Rachels's influential discussion (1999: Ch 2), that the extent of moral differences between societies is not as great as might appear. On the other hand, I am most attracted to a normative ethical theory that does not value harmony merely as a means, but instead gives it a final value that is to be promoted, or at least prized in some way. Although I do not yet believe ubuntu qua moral theory I have a proposed, I do believe it is a serious competitor to other moral theories in English-speaking philosophy. ${ }^{2}$

To reconcile these views, I need to provide some reason for thinking that moral differences are not as deep as they appear, without explaining the differences away in terms of the merely instrumental value of harmony. I do not have the space to do this here, but merely note two strategies that are promising and worth pursuing elsewhere. First, one could appeal to evolutionary reasons for thinking that the species as a whole would refer to the same basic property with "morality." Socio-biological considerations regarding the kind of cooperative behaviour among finite agents requisite for them to pass on their genes might do the trick. Second, one could seek to make the list of intuitions that are common to Africans and Westerns much larger than the list I offer in my article. Indeed, I think the overlap is much greater than merely the six intuitions I have listed (2007a: 324).

Before turning to normative ethics, I want to make one more metaethical point. Wood's analysis suggests that sub-Saharan Africans probably value harmony merely instrumentally, or should do so, given how instrumentally valuable it has been for their societies. That inference, I submit, is not fallacious, but is not clearly as strong as I gather Wood believes it to be. I grant Wood that harmony has been enormously instrumentally useful for traditional African societies, but do not infer from this fact that they value it merely as a means or should do so. For one, many African intellectuals, at least, would like to see much more identity and solidarity in modern, industrial societies. Consider, for instance, Kwasi Wiredu on consensus-based democracy (1996: Pt. 4), Desmond Tutu (1999) on reconciliatory criminal justice, Muxe Nkondo (nd) on the need to foster national identity, Reuel Khoza (2005) on a participatory workplace, and the continued interest of many African intelligentsia in finding a kind of market economy that is more humane than even Scandinavian social democracy.

For another, harmony, as I conceive of it, is a very strong candidate for having final moral value. As I point out (2007a), a relationship in which people identify with one another and act for one another's sake is more or less what English-speakers mean by "friendship" or a broad sense of "love." Conceiving of killing, raping, stealing, deceiv-

1 Which is not clearly Wood's, or at least not Wood's sole, suggestion. There are times when analyzing the differences between societies that Wood maintains that Africans have been correct to prize harmony to a greater degree than Westerners, and apparently not for merely instrumental reasons. Consider, e.g., his discussion of cooperation and competition.

2 Indeed, I think that only Kantianism in the guise of the formula of humanity gives U6 or something close to it a run for its money; the latter strikes me as far more attractive than utilitarianism, eudaimonism, egoism, contractualism, divine command theory and remaining players in the field. 
ing, promise-breaking and the like as unfriendly behaviour, and, more specifically, as failures to share a sense of self with others or to exhibit good-will toward them, is a prima facie powerful explanation of why these actions are wrong. The conception of harmonious relationships as being highly good for their own sake and as grounding our moral obligations is worth developing as an alternative to Wood's traditional suggestion that it is rather individual dignity, well-being or self-development that alone has these features.

Suppose, now, that harmony were a superlative final good that grounds morality. How should we respond to it, in order to perform the right act? My basic proposal in the article was that we should promote it. Wood objects, quite plausibly, that such a strictly consequentialist or teleological conception of how to respond to harmony has the counterintuitive implication that one should be discordant (i.e., conceive of oneself in opposition to others and exhibit ill-will) or otherwise treat people poorly when it would produce only marginal gains in harmony in the long-run. He points out that the principle I sketch would counterintuitively "require violating ubuntu as a way of life whenever there might be any increase in social harmony or community as a consequence." As an alternative, Wood suggests that the proper way to respond to the final value of harmony would be to live in accordance with harmony, to embody it or to act harmoniously. One could also suggest a more explicitly expressive version of the principle, so that one's basic obligation is to prize harmony or to show respect for it.

I am absolutely convinced by Wood's criticism of U6, the bald injunction to promote harmony and to reduce discord. I noted this, very briefly and implicitly, in the initial article, saying that a fuller and more accurate theoretical account of ubuntu would require deontological restrictions built into it (2007a: 338, 341). Wood has given us one way to build them in, and it is a strategy that I am happy to acknowledge must be seriously considered. In other work since "Toward an African Moral Theory," however, I have tried two different strategies, and I close my discussion of Wood by laying out these alternatives. My view is that they are strategies that need to be developed and evaluated alongside development of Wood's strategy, with the aim of seeing which is ultimately more attractive.

What my two other deontological strategies have in common is that they retain a fundamental goal for moral agents. That is, they both prescribe the aim of promoting harmony and reducing discord, but subject to the non-violation of certain side-constraints. In "Developing an African Moral Theory" (unpublished), I suggest that one's aim should be to promote harmony without using substantial discord as a means, unless the discord is proportionately distributed among those who have been discordant and is necessary for promoting harmony among those who have not. Such a principle, I have argued, accounts well for many intuitive human rights, both negative and positive. Elsewhere, in "Ubuntu, Dignity and Liability to be Killed" (unpublished), I have explored expressly incorporating a notion of individual dignity at the theoretical heart of ubuntu, such that an act is right insofar as it promotes harmony in the long-term but without degrading the individual's dignity, which she has in virtue of being capable of engaging in harmonious relationships.

My hunch is that these alternative strategies are logically related, but leave that claim aside for now. The main point here is that they are prima facie attractive ways of accounting for the clear deontological aspect of ubuntu, but that they probably differ from Wood's strategy in that they still posit a goal to agents that they must pursue in certain ways rather than others. My reason for finding it worth exploring a goal-based 
theory with side-constraints is that such a principle, on the face of it, best accommodates a number arguments that African literati have offered for certain policies. For instance, Wiredu's defence of a consensus-based democracy is that it would have the long-term effect of preventing disaffected minorities, Tutu's advocacy of non-retributive justice (at least when it comes to responding to apartheid-era crimes) is that it is most likely to promote reconciliation, and the injunction to create children is best explained as a requirement to promote harmonious relationships. However, I readily admit that this evidence is not decisive, and I look forward to thinking about Wood's powerful suggestion in future work.

\section{The Status of an African Moral Theory: Reply to Ramose}

With regard to all the contributions to this symposium, I am pleased to have this reply in which to clarify and deepen my thinking and to take the issues farther. In the case of Mogobe Ramose's contribution, however, I feel lucky to be able to reply since he is the most critical of the commentators, routinely finding my claims "far fetched and problematical," "exaggerated and unsubstantiated," "tenuous," "questionable," "neither illuminating nor convincing," "neither credible nor sustainable," "on weak ground," relying "only on rather dubious credibility," lacking a "clearly identified and specific standpoint," and (best of all!) addressing "a cadaverous caricature of ubuntu." I respect Ramose as my elder in the South African philosophical community, i.e., as someone from whom to learn, but I frankly wish that he had been able to read my work in a more charitable way.

I begin my reply to Ramose by addressing three issues that I am thankful he has raised since they are philosophically important and require clarifying central aspects of my position. First off, Ramose claims that in seeking a single moral principle, I am implicitly after "immutability, essentiality and eternity," which, in turn, is a matter of "absolutism and dogmatism." It is true that I am oriented toward monism rather than pluralism, but that does not logically imply anything about advocating an unchangeable and essentialist ethic for sub-Saharan Africa, something I have tried hard to avoid doing. I remind the reader ${ }^{3}$ that I am aiming to capture mere tendencies or recurrent themes found in this part of the world, not anything that I have suggested is permanent or universal there. Would it not be terribly interesting if a single principle could indeed capture the myriad particular duties that a spatio-temporally large swathe of Africans intuitively think are binding? It might turn out that a single principle is insufficient to do so and that only a handful of principles can, but that could be known with a great degree of confidence only after a very intensive search for an adequate single principle has taken place.

The second philosophically substantive issue that Ramose raises concerns the meaning and aptness of seeking a "distinctively African" moral theory. I think it is fair for Ramose to judge my article to be unclear about these issues and to push me for more. I hope that my discussion in the introduction to this symposium, and in what follows, will help to clarify my thinking. Roughly, a moral theory counts as "African" for me insofar as it is informed and defended by beliefs that are common among peoples in sub-Saharan African, and particularly beliefs that are more common there than among Western societies. A moral theory counts as "distinctive" insofar as it differs from what is dominant in contemporary Anglo-American and Continental philosophy. It is of course logically possible for something to count as "African" but not as "distinc-

3 See (2007a: 324) as well as my discussion earlier in this symposium, "The Motivation for "Toward an African Moral Theory'." 
tive" (and vice versa), given these meanings of the terms. I have simply made it my goal to find out whether there is a principle that has both features (among others), since achieving that goal would be of particular philosophical interest at a global level. Adopting such a goal implies neither that finding a principle both African and distinctive would alone be of such interest, nor that all that is African is distinctive. Furthermore, these definitions leave open the possibility that what counts as "African" can also be found elsewhere in the world, an implication that strikes me as apt. Intuitively, something can be characteristically African without being "unique" to Africa in the sense of not being found anywhere else at all.

Third, Ramose objects to the methodology I use to articulate and defend a fundamental moral principle, maintaining that his own is to be preferred. As Ramose notes in his contribution, he grounds his interpretation of ubuntu as an ethic on the etymology of the term. Since I do not do this, or at least since I employ a strictly analytic methodology, Ramose claims I am not entitled to the claim of an "African" moral theory. ${ }^{4}$ I wish I had the space to discuss Ramose's method in some depth. In the future, I would find it rewarding to debate issues of methodology with him; he has considered them with care and I think I would learn from thinking through the advantages of disadvantages of both his and mine. Here, I reply merely by noting that, while there is a sense in which my methodology is "Western," it would not follow from this that the moral theory I defend is thereby "Western" or "non-African," for two reasons.

For one, the argumentative defence of the theory appeals to moral judgments that are more common in Africa than in the West. For another, it is incorrect to assert that a principle that has been justified by a "Western" methodology is ipso facto best construed as "Western" or "non-African." Consider an analogy. Suppose Western science showed that a certain plant particularly indigenous to South Africa has healing powers. I submit that it would be sensible to call the treatment a "South African" one, despite the existence of a Western proof that it is effective. Similarly, I am trying to show that the moral principle (or something close to it) that I find in the works of certain African theorists can be justified by using the methods of analytic philosophy. The method alone, supposing it is "Western," should not be sufficient to disqualify the defended principle as "African."

Ramose also takes issue with my article for points that are less philosophical and more exegetical. For example, he believes that I have given his work a cramped reading, "reducing" and "limiting" it to mere etymology. However, I do no such thing. While I do in a footnote point out that he has discussed the etymology of the word "ubuntu" (2007a: 323, n 5), such a reference does not suggest, or at the very least was not meant to suggest, that this is all he has done. Indeed, elsewhere in my article I cite Ramose several times for additional points from his work on ubuntu.

Ramose also claims that I "dismiss" some work by other African thinkers, but, again, I do no such thing. I do aim to differentiate the kind of project I am undertaking, namely, analytic normative ethical theory, with what I take to be different kinds of projects in African ethics, particularly the aim of recounting and critically reflecting on the moral beliefs of a particular sub-Saharan people. But as I said in my article, "I do not mean to disparage these discussions; I aim merely to distinguish them from this

4 Below Ramose claims that other African thinkers have shared my aim and method. If that were true, then the implication would be that they, too, have failed to produce an "African" moral theory.

5 My colleague Lucy Allais has reminded me that it might also be dubious to claim analytic reasoning to be "Western," for surely plenty of Africans and people throughout the world think with special attention paid to clarity, logic and principle. 
one" (2007a: 321, n 1). I believe that there are lots of projects besides mine that are worth doing for their own sake, and, furthermore, I would have had zero ability to undertake mine had I not relied on them.

An additional place where Ramose believes I have been unfair with regard to other authors is my claim that "no one" in the English-speaking literature has both had the primary aim of seeking a single basic, comprehensive (and secular) moral principle that best accounts for intuitions more common in Africa than in the West and sought to realize the aim in a systematic, analytic way (2007a: 321). It is not important whether this claim is true or not, ${ }^{6}$ it was not the aim of my article to establish it, and I will not attempt to establish it here. However, since discussing Ramose's reasons for doubting the claim would bring up some important issues with regard to the literature on African ethics, I do so now.

Aptly, Ramose provides putative counterexamples of others who have had the same primary aim as me and used the same means to achieve it. He takes me to task for apparently not paying attention to some texts that he repeatedly notes were published in English at least five years before the publication of my article, namely, some works by Kwasi Wiredu and Bénézet Bujo. There are two very odd aspects of Ramose's point, here. First off, I cite precisely the works that Ramose appeals to in my article, and do so many times.7 Second, Ramose himself claims that Wiredu and Bujo "do not speak to Metz' conception of 'normative theory' as 'the articulation and justification of a comprehensive, basic norm that is intended to account for what all morally right actions have in common as distinct from wrong actions'." In sum, in the article I do demonstrate familiarity with the texts that Ramose suggests that I am not aware of, and Ramose's own characterization of these texts explicitly says that they do not have my aim as their primary one.

There are deeper and more important points to make about the way Wiredu's and Bujo's works relate to mine. At one point, Ramose says that Wiredu does propose, with respect to the Akan people, "the ethical principle around which all the moral activities described revolve," namely, the principle that life is mutual aid. I read Wiredu differently. Wiredu does refer to a basic principle for the Akan, but it is not a principle of mutual aid that he picks out. "(W)e may elicit from the Akan maxim under discussion the view that sympathetic impartiality is the first principle of all morals. This principle is the logical basis of the golden rule, or the obverse of it that is frequently heard in Akan ethical talk, namely, 'Do not do onto others what you would not that they do onto you"' (1992: 198). Here is what is true: I did not discuss this moral theory in my article, and I should have given it some attention.

What bearing would addressing the golden rule have had on my aim in "Toward an African Moral Theory"? Insofar as I am explicitly seeking a principle that differs from what is dominant in the West ${ }^{8}$ the golden rule is obviously not a contender. Furthermore, I believe the golden rule is unable to account for many of the intuitions that I seek to capture. For instance, I have encountered no reason to think that punishment is categorically forbidden in many African cultures, but the golden rule, on the most

6 If it were merely approximately true, it would be enough to justify undertaking the project in "Toward an African Moral Theory."

7 My first citation in 2007a of Wiredu's "Moral Foundations of an African Culture" is at p. 325 n 9 and my first citation of Bujo's Foundations of an African Ethic is at p. $327 \mathrm{n} 23$. I leave to the curious reader the pedantic task of counting up how many times I thereafter cite them again. I have not yet become acquainted with Bujo's The Ethical Dimension of Community, and am glad to have been pointed to it.

8 See my discussion earlier in this symposium, "The Motivation for 'Toward an African Moral Theory'." 
straightforward understanding of it, rules out punishment (as Kant noted long ago in section two of the Groundwork). After all, the golden rule would instruct a judge, when responding to an offender, to consider whether he would like to be punished (perhaps if he were in the offender's shoes), and since virtually no judge would want to be punished himself, it appears invariably impermissible for a judge to penalize an offender.

There are replies to this problem that appeal to some notion of "reasonable" wants or the desires of an "objective" self, but such appeals, I submit, are implicitly invoking some other moral principle about what we should value. So, for instance, if we say that we should want to be punished sometimes, since punishment would teach us a moral lesson and reform our characters, then we are basing moral judgment on these latter goods and not on the fact that we do or do not want something. An additional sort of reply is to qualify the golden rule to say that we should treat other innocents as we would want to be treated. However, then the principle would clearly not be a candidate for a comprehensive moral theory, since it would fail to provide guidance about how to respond to the guilty.

The deep problem with the golden rule, I think, is that it appeals to what we in fact want (or would want if we were in another person's situation), and people's wants vary widely and can be intuitively inappropriate. Suppose, for instance, I believe that intense market activity is appropriate for economic production, since it will, say, best produce goods that people want and force not only firms to be efficient but also individuals to be self-reliant and entrepreneurial. Imagine that my firm is driving yours out of business, and I now wonder whether it should continue to do so. If I were in your situation, I would not like the fact that my company is tanking, and yet I could still want to be driven out. I would believe that, for the long-term benefit of the community, I should be forced to produce a different widget that is of more value to others, and we may imagine that I would have strong altruistic desires. In that event, the rule saying that I should treat others the way I want to be treated (or would want to be treated, were I in their shoes) would permit me to be extremely competitive with regard to you, something that many African thinkers, including Wiredu and Ramose, believe is objectionable.

As for Bujo's relationship to me, I do discuss his theoretical interpretations(s) of African ethics in my article, and I acknowledge that his work comes close to the kind of project I undertake. However, in support of the idea that Bujo's primary aim differs from mine, consider the way he characterizes his project: "I never forget that the ultimate goal of the whole endeavor must be the better understanding and living, in a genuinely black African context, of the realities connected to the Christian faith" (2001: xiv). The primary aim for Bujo is not the development of a normative ethical theory, let alone an explicitly secular one, as it is in my case (2007a: 328).

Furthermore, Bujo's methodology is not saliently characterized by the method of positing of a general principle, posing a particular counterexample, reformulating the general principle so as to avoid the counterexample, posing a new counterexample to the reformulated principle, revising the principle yet again, and so on. That is the kind of methodology I have in mind when I speak of seeking to achieve my aim in a "systematic, analytic way." Indeed, Bujo explicitly eschews exclusively relying on such a method when he says, "Black African rationality is much more inclusive. In the process of establishing norms for ethical-moral conduct, it admits the contribution of that which cannot be justified in terms of reason alone," (2001: 10) or, more carefully, jus- 
tified in terms of the particular sort of rationality associated with the methodology I employ. Bujo believes that the kind of rational analysis I use cannot easily ground the supernaturalism that is at the heart of his worldview (2001: 10-11).

\section{Intuitions in Moral Theory: Reply to Farland}

Douglas Farland's discussion is about the role that intuitions play in the articulation and defence of my favoured interpretation of ubuntu as a moral theory. I claim that we should believe that the best principled understanding of ubuntu as an ethic is, roughly, one saying that we're obligated to promote harmony and reduce discord of a certain kind and in certain ways. And I maintain that a strong reason to believe this theory is that, relative to other competitors in the literature, it best entails and explains twelve intuitions that are recurrent in African ethical writings (six of which are more common among Africans than Westerners). Farland marshals two major kinds of criticisms against this rationale. On the one hand, he argues that the intuitions I invoke are not the correct ones, and, on the other, he argues that, even if they were, the theory I articulate would not provide an attractive unification of them. I welcome this opportunity to clarify and defend my project from criticisms that aim at its argumentative heart.

One of Farland's points is that not all the twelve intuitions I appeal to are "foundational" or "self-evident." Since I am not a foundationalist with regard to the epistemic justification of moral theory, I readily grant the point, when construed in this strong form. I do not claim that any of the intuitions I invoke are "basic" in the sense typical to foundationalism, that is, I do not mean to suggest that they are strongly justified without needing justification from anything but themselves. That is true even for the six "universal" intuitions that I claim are held by a very large majority of people in both Africa and the West.

In the first instance, I am making a different, dialectical argument, that is, making an argument that should have appeal, given adherence to a certain standpoint. The twelve intuitions I invoke are, I claim, plausible and less controversial than the theories I am evaluating, from the perspective of at least those who have written on African ethics and of sub-Saharan Africans more generally, supposing the literati substantially reflect their views. They have good reason to believe the principle that one's basic duty is (roughly) to promote harmonious relationships, since that theory unifies moral judgments that they believe to be commonsensical. In short, I use the intuitions not so much as a foundational base on which to build, but rather more as starting points in seeking reflective equilibrium in African moral thinking. I am willing to say that the intuitive beliefs are provisional and that some of their justificatory force comes from something other than themselves (whether that be other beliefs, reliable mechanisms, virtuous processes or whatever). All I really want is the claim that there is more agreement on the intuitions in the African ethical literature than there is on the principles that might be advanced to capture the intuitions, and that my principle captures them better than the others one finds.

However, Farland's criticism ultimately does apply to this conception of the argument I am advancing. He denies that all of the twelve judgments I articulate are uncontested among those writing on African ethics. First, he questions whether people (or Africans in particular) would deem "stealing unnecessary goods" to be wrong; either the owner finds them unnecessary, in which case the theft is not so bad, or the thief invariably finds the money he could obtain from the goods to be necessary. However, by an "unnecessary" good I mean a thing or what could be obtained from it that is not re- 
quired to meet any basic needs of the thief (or someone to whom he would give the stolen item). So, my point is that theft is wrong at least in the case in which the beneficiary of the theft is already well off, e.g., where someone steals a car simply because she does not like the colour of the one she already has. That is, I presume, uncontroversial.

Second, Farland points out that it is not intuitively wrong, either for him or for Africans, to "discriminate on a racial basis" when awarding education or employment, for affirmative action programmes are often thought to be justified on compensatory grounds. Now, when I spoke of "discrimination," I meant to exclude such a case. My point is that, with regard to ideal theory, race is a morally pernicious ground on which to distribute opportunities when it is not itself a qualification, even if race can be an acceptable ground for distribution when it comes to non-ideal theory, i.e., with regard to how to rectify violations of ideal theory. It might help to say that it is pro tanto wrong "to allocate opportunities on a racial basis, at least when race is not an opportunity-related qualification and is not being used to redress previous discrimination on racial grounds."

Third, Farland thinks that retributive judgment is more prominent in African thinking than I suggest. In support of his view, he points out that the Zulu people have sometimes imposed the death penalty for murder. In reply, note that the quotation Farland provides is unclear about the reason why the death penalty has been used (speaking merely of a vague "that he may follow the man he has killed"), meaning that, as it stands, it is not any evidence of retributive thinking. If capital punishment was imposed in order to protect the community from the anger of ancestors, to incapacitate the offender, to deter others from committing similar crimes, or to make the community feel safer, then there is no retributive aim involved. Furthermore, I do not make the claim that there are absolutely no retributive sentiments among sub-Saharan African communities or intellectuals. Instead, my point is that it is far from the dominant orientation, when such people are expressing considered judgment about what they take to be sound moral norms. In my encounter with philosophical and anthropological literature on African moral thinking, I have not come across the view that punishing someone merely for backward-looking reasons such as desert should be the primary function of criminal justice. In contrast, I have very often encountered the idea that its central aim should be the forward-looking one of facilitating reconciliation.

Fourth, Farland claims that a number of the intuitions I appeal to are not judgments of actions that have pro tanto wrongness, where they alone are the proper intuitive ground on which to construct a moral view. Farland points out that many of the intuitions have a structure different from the one appealed to by W. D. Ross, the moral philosopher who initially discussed the concept of pro tanto wrongness with care. Ross claims that certain properties, or action-types with these properties, have wrongness or rightness to some degree, e.g., maleficence or maleficent actions are wrong to an extent. In contrast, Farland claims, the intuitions I address include "descriptions of acts that often receive disapproving verdicts in African societies, rather than ways of identifying their wrong-making features." For him, the four cases where I have gone astray include: failure to promote family, failure to participate in a community's way of life, adopting policy that has not been the object of consensus, and basing economic production on predominantly self-interested strategies. Farland's main reason for thinking that these four cases are not instances of judgments of pro tanto wrongness is that in these cases we cannot specify wrongness independently of the act itself. Giving 
money to Oxfam would not be an instance of pro tanto rightness, according to Farland, whereas beneficence would be, since beneficence is a property that could be exhibited by many actions and donating to a specify charity could not be. The above four cases do seem more like the charity case than like beneficence in this respect. ${ }^{9}$

In reply, even if it were true that I have not, in these four cases, pointed out pro tanto wrongness as such, it would not follow that what I have done is to present "overall verdicts" of actions (which verdicts could conflict with other intuitions, rendering inconsistent the set of intuitions I lay out). I am pretty confident that the four are not well described as "overall verdicts" of permissibility, for many Africans would, e.g., judge not only Nelson Mandela to have been all things considered correct to have put politics before family, but also hierarchical decision-making to be acceptable in emergency situations where consensus-seeking would irreparably impair the achievement of very urgent benefits for society. Instead of listing four all things considered judgments of certain actions, perhaps what I have presented are four act-tokens that instantiate pro tanto wrongness. They are behaviours or practices that are (particularly) pro tanto wrong, even if they are not properties of wrongness or action-types with wrongness.

Furthermore, even if, in these four cases, I have not indicated what the pro tanto wrongness itself is, why should this matter, if I am correct that they are particular actions that indeed exhibit pro tanto wrongness? For the sake of consistency, there is admittedly reason to present either properties, act-types or act-tokens exclusively, and Farland's point indicates a need for me to return to the literature to see whether I could do this. What I presented were intuitions that I thought captured what I had read, but what I read might admit of more uniformity than I offered in the article. I am grateful to Farland for making me aware of the motley bunch of judgments I have listed and to consider whether this is the best one could do. However, if I am correct that the four action-tokens uncontroversially instantiate salient pro tanto wrongness for a large number of sub-Saharan Africans, that would seem a sufficient basis by which to evaluate a moral theory. It is a strike against a moral theory if it does not entail that and explain why these act-tokens have pro tanto wrongness, and a plus for it if it can.

I appreciate the push Farland has given me to consider the nature of the intuitions I invoke and of how they relate to each other in ways I had not before. I now turn to his second major sort of criticism of my article, namely, that the theory I offer as a unification of the intuitions is unattractive. Most troubling on this score, Farland claims that the theory I have offered ironically "displaces the various intuitions, leaving them with very little role to play in our moral thinking." Although my theory could capture "general truths" about morality, it cannot capture judgments about pro tanto wrongness, for they would have "no longer any contributory role to play once the comprehensive basic norm has been established."

Consider an example, to make Farland's point clear. Actions that are pro tanto wrong are invariably immoral to some degree (where the action could nonetheless be all things considered morally justified). Actions that are typically or generally wrong, in contrast, are those that are often, but not always, wrong to some degree. So, for instance, maleficence (for Ross) is pro tanto wrong, i.e., it is always immoral to some degree. In contrast, killing innocents is merely typically wrong and is not always wrong to some degree (e.g., for most professional ethicists, killing an innocent is not wrong at all in the most basic trolley case of redirecting the train to kill one instead of

9 Though perhaps the one about lack of non-consensual policy does not? 
five). Farland's claim is that there is something intrinsic to at least the teleological moral theory I have proposed that renders it in principle able to account for why killing innocents is typically wrong but not for why anything (either killing innocents or maleficence) is pro tanto wrong.

The reason for the alleged inability to capture pro tanto wrongness is that once a single basic goal is prescribed for a moral agent, an action cannot be right merely to some degree; instead, whether an action is right or not will be an all or nothing matter about whether it achieves the goal. So, to continue with the previous example, if the basic goal of a moral agent were to promote harmony of a certain kind, and if a particular instance of killing an innocent would best promote harmony, then there would be nothing at all wrong with the act, i.e., no pro tanto wrongness that would remain. And to use another example from Farland, "It is not as though we need to think about the fact that failing to start a family is pro tanto wrong if we know that failing to promote harmony in the community is wrong.... The thought is that it is generally wrong to fail to have children but it may not be wrong in this instance if failing to have them will promote harmony."

However, I suspect that even a plural consequentialism à la G. E. Moore, David Brink and Peter Railton can be understood to account for pro tanto duties, and if it can, then so can ubuntu as a consequentialist moral theory. Suppose one held that an action is pro tanto right insofar as it promotes final goods such as pleasure, beauty, life, knowledge, autonomy and desert and pro tanto wrong insofar as it promotes the parallel disvalues. And suppose that the act that should be all things considered performed is the one that has the highest net balance of pro tanto rightness over wrongness. So, killing one when necessary to save five could be deemed wrong to some degree (say, for the loss of one life or autonomous agent), but justified on the whole. ${ }^{10}$ If that makes sense, then so would it make sense for ubuntu as a teleological moral theory to adopt a similar structure. Here, killing innocents and failing to raise children can be salient pro tanto wrong-makers, i.e., can be in themselves particularly bad failures to some degree to promote harmony, even if they turn out in a given instance to be what promotes harmony the most in the long run.

I am not sure whether this reply to Farland is successful or not, but I am certain that his point raises questions to which I need to give more consideration. Does my reply to Farland rest on a sense of "pro tanto duty" that is weaker than the one he deems central to moral thinking? Does he intend his criticism of the self-defeating theoretical attempt to account for pro tanto duties to apply only to teleological moral theories or also to deontological ones? To avoid the problem of self-defeat, must we avoid a normative theory altogether and opt for a merely evaluative principle, as Farland suggests at the end of his article? These are difficult and important questions that I am glad that Farland has made me aware of the need to answer with care in future work.

\section{Reasons for Action: Reply to van Niekerk}

Recall that I am most attracted to an interpretation of ubuntu qua moral theory according to which at least some ${ }^{11}$ basic moral status inheres in certain relationships between people. The view that an act is right insofar as it promotes relationships of particular

10 Cf. Jeremy Bentham and John Stuart Mill who speak of actions being right as they "tend toward" the realization of utility.

11 I doubt that the most attractive understanding of ubuntu would ground fundamental moral importance solely in relationships; some notion of dignity that is internal to the individual is probably essential. For 
kinds and in particular ways entails two logically distinct conceptions of basic reasons for action. ${ }^{12}$ First, it entails that some of our basic moral reasons for action are relational rather than intrinsic. For instance, the basic explanation of why I ought not kill an innocent person for money appeals not to any facts internal to me or to the innocent, but to facts about the way we interact. Whereas utilitarianism entails that my basic reason not to kill an innocent is constituted by facts about the pleasurable and painful experiences that are inherent to my body and to the bodies of others affected by my action, the conception of ubuntu I am articulating would instead entail that the reason not to perform such an action is, at bottom, a function of being an inappropriate way to relate to another. Second, this conception of moral status entails that some of our basic moral reasons for action are other-regarding and not merely self-regarding. Whereas an egoist would say that my basic reason not to kill an innocent is always constituted by facts about my long-term well-being, my favoured interpretation of ubuntu would rather say that the way I treat others grounds the reason not to perform this action. ${ }^{13}$

Instead of my relational and other-regarding conception of fundamental moral reasons for action, Jason van Niekerk aims to defend an understanding of ubuntu grounded on an intrinsic and self-regarding, or what he calls an "autocentric," conception. According to this perspective, one's basic moral reason for action is only one's self-development. To live a genuinely human life, you must relate to others in certain ways, where it is not the relationship that grounds the ultimate justificatory reason to perform the action, but rather solely the fact that the individual who performs the act can, by virtue of engaging in the relationship, live a genuinely human life. Such a view, as van Niekerk points out, has fascinating and under-explored affinities with eudaimonism. ${ }^{14}$

One reason I favour the relational and other-regarding conception of ubuntu is that it differs markedly from views that are dominant in Western philosophy. That strikes me as one major reason to work on developing it. However, I believe that an additional reason to develop it, as opposed to van Niekerk's autocentric perspective, is that it is more plausible. Van Niekerk aims to respond to three criticisms I make of the autocentric perspective, and his responses have given me pause. I have been forced to reconsider my views, as I acknowledge that the interpretation of ubuntu that van Niekerk articulates is powerful in itself and fits with a lot of discourse about ubuntu, particularly the maxim that a person is a person through other persons. However, upon reflection, I find van Niekerk's defence as yet unconvincing.

an attempt to develop the sort of conception of dignity that ubuntu qua moral theory ought to include, see Metz, "Ubuntu, Dignity and Liability to be Killed."

12 Supposing, as I do, that a morally right act necessarily provides pro tanto reason for action, which reason obtains apart from being grounded upon some other reason. Elsewhere (Metz, 2008), I articulate the metaphysical considerations why I think that morally right actions necessarily provide pro tanto basic reasons.

13 Note that the relational/intrinsic distinction cross-cuts the self-regarding/other-regarding distinction. A relational account of basic moral reasons entails an other-regarding conception (since relationships, as conceived here, are not merely internal to the self), and a self-regarding conception obviously entails an intrinsic account. However, an other-regarding conception of basic moral reasons need not be relational, and an intrinsic account need not be self-regarding; insofar as utilitarian and Kantian conceptions of basic moral reasons place them outside of oneself, they do so in the pleasurable experiences or dignified agency (respectively) that is inherent to other persons, and hence they include other-regarding and intrinsic conceptions of basic moral reasons for action.

14 Which affinities van Niekerk is currently exploring in his $\mathrm{PhD}$ thesis at the University of the Witwatersrand Philosophy Department, "Ubuntu and Moral Value." 
One criticism I make is that an autocratic conception of right action oddly permits killing innocents when necessary to maximize one's self-development. If nothing beside the self ever grounds a reason to act, then the self may use anything at its disposal for its sake. An other-regarding account does not face this problem, since something outside the self has an independent and fundamental claim on the way the self should behave. I point out that a principled adjustment to the autocentric perspective, one that builds in rights as side-constraints on the pursuit of the goal of self-development, could avoid this objection. Van Niekerk, however, suggests an alternative way of resolving the problem, since he is concerned - correctly, I think - that rights are more plausibly grounded on other-regarding than self-regarding concerns, so that the monistic elegance of the theory would be lost.

Instead, van Niekerk suggests that killing an innocent in order to maximize one's self-development simply would not succeed, since the act of killing an innocent would likely affect one's character in such a way to make one unable to develop oneself in the right sort of way afterward. I think that this will sometimes be true, but that empirical generalization is not sufficient and that principled universality alone is. In other words, there will be cases in which killing an innocent would not impair one's character so badly as to make further self-development unlikely. For a hypothetical case, consider a slight change to the original organs one. Suppose that one needs organs to survive and hence develop oneself in the requisite way, and that none are available by consent. Imagine that one kills an innocent to obtain the organs and then immediately takes a pill to forget having done so. In a case in which one is unlikely to remember having killed an innocent, one may, counterintuitively, be justified in doing so, for such an action might be necessary to realize oneself in the long-term. A relational and other-regarding account of basic moral reasons clearly does not as readily face this problem. However, it might be that van Niekerk's intrinsic and self-regarding view has more promising resources for resolving the problem, as I point out below.

The second criticism I make of autocentric theories of morality is that they too often forbid self-sacrifice. Since others lack moral status, one can, it seems, never be justified in killing oneself, or in letting oneself be killed, for the sake of others. In a ferryboat accident in which there are not enough lifeboats to go around, an autocentric theory seems unable to permit volunteering to give up one's life for the sake of another or abiding by a random or otherwise fair procedure for determining who gets to live.

Here, van Niekerk is sympathetic to the idea that failure to give up one's life in such a situation would be such an improper way to relate to others that "recovery" afterward would be impossible. He claims that the aim of self-development should not be understood to be a state of affairs in which certain relationships consisting of varying amounts of final value have been maximized in the long run, but instead the realization of a life with a certain overall pattern. Van Niekerk's autocentrism posits a goal to moral agents that is captured by aesthetic metaphors of living life as a good story or song, one major element of which is having an attitude of caring for others' lives and well-being. Were one to refrain from self-sacrifice in order to continue one's narrative, then the narrative would in fact be irreparably damaged by that single instance of dreadful composition or performance.

Note that van Niekerk could invoke this powerful line when attempting to show that his autocentric perspective can forbid the intuitively unjustified sacrifice of others. Presumably killing another would also be a blight on the narrative of the agent's life where that narrative must include the theme of acting for the sake of others - for 
which she could not compensate, at least if failure to sacrifice herself would be such a blight.

Van Niekerk's suggestion is compelling in its own right as an assertoric claim, and, furthermore, has dialectical pull against me in particular, as I have elsewhere acknowledged several respects in which the meaning, or more generally, value of a life can be affected by "holistic" considerations, i.e., by the pattern of the life as a whole as opposed to the sum of its parts (Metz, 2007b: 209-10). However, I balk at the suggestion that holistic considerations exhaust the value of a life, or that they take lexical priority over aggregative considerations, one of which claims van Niekerk needs in order for his response to work. I am willing to accept that holism plays an irreducible role in the value of a life, and while it is less clear to me how it might plausibly bear on our judgments of moral excellence (as opposed to, say, meaningfulness or of nonmoral perfection), I am willing to grant, here, that it does. What I am keen to deny is the view that the value of a life's parts can never (or only rarely) be of more value than its holistic facets, a claim that van Niekerk is implicitly committed to in order to block my suggestion that self-development too often or in the wrong instances forbids self-sacrifice.

To flesh this out, return to van Niekerk's aesthetic metaphor and consider a piece of chamber music with four parts. Intuitively, we think that it is possible for the second part to be bad and the other three parts to be good, and for this to be so even if the piece as a whole is marred by the weakness of the second part. We also think that such a piece of music could have a great degree of aesthetic value and be worth listening to, despite the fact that the second part is poor and the piece as a whole does not work. Of course, if it is true that the piece as a whole does not work, then one might suggest listening only to the parts, making each a whole unto itself. That is indeed what should be done, if possible. But suppose it were not possible; suppose one's only choices (analogous to life itself, which cannot be digitized and remixed) are either to stop listening before the second part comes, without otherwise acquiring access to the third and fourth parts, or to listen to the whole thing. In that case, it could be worth listening to the whole composition, despite the fact that the composition qua whole is not worth listening to; for the value of the parts of the work could make it worthwhile suffering through the second part to get to the third and fourth. Similarly, from the perspective that moral rightness is merely a function of self-development, we can expect there to be irreducible summative factors that often make it morally worth continuing to live, despite the fact that terrible parts such as killing others or refusing to kill oneself have irreparably marred the whole.

I now turn to the third criticism I make of an autocentric approach to moral theory, namely, that even if it could entail that killing others is unjustified when we intuitively find it so and that killing oneself is justified when we intuitively find it so, it would provide the incorrect kind of explanation for these judgments. I claim that the self-regarding element of autocentrism grounds an implausible account of why we may not kill others and may kill ourselves, namely, that it would be best for us. The only ultimate moral reason to perform an action, on van Niekerk's view, is that it will develop ourselves in a genuinely human way, but this, I claim, is not the correct reason either for refraining from killing another or, indeed, for killing oneself. Van Niekerk offers two reasons to think that it might in fact be the correct reason. First, he points out ${ }^{15}$ that, on his account, an agent who develops herself in the right way would have the motive of acting for the sake of others. Someone who has ubuntu, for van Niekerk, is someone who does not perform actions for the sake of herself, and who thereby (and not merely as a result) does precisely what is best for herself. He suggests that the

15 As has Augustine Shutte in conversation and correspondence. 
other-directed focus of the agent's motive is sufficient to account for our intuitions about morality; we do not also need an other-regarding account of practical reason to do so. Second, van Niekerk claims that a virtue of his account is the ability to provide a direct answer to the amoralist, the person who questions what reason there is to make sacrifices, perhaps of life or happiness, for the sake of others. Van Niekerk's theory can say straightaway that the reason to help others is that, in doing so, one is helping oneself, something the amoralist standardly takes as a good reason for action.

However, the relational and other-regarding account I offer is equally able to respond to the amoralist, and is, I maintain, necessary to capture our intuitions about the respect in which morality involves a focus beyond oneself. First, in terms of the amoralist, it is open to me to accept that there are self-regarding reasons for helping and not harming others. Suppose van Niekerk were correct that one's own good is constituted by a relationship that involves, perhaps among other things, acting for the sake of other people. In that event, if the amoralist came along, I could point out to him that there are (non-moral) self-regarding reasons for him to make sacrifices of certain kinds for others as well as note that there are also other-regarding reasons (of morality). True, it is not qua moral theory that I am able to reply to the amoralist, but that should be acceptable, for I could nonetheless show that acting in accordance with the moral theory has non-moral benefits for the amoralist (which benefits do not exhaust the reasons an agent has for so acting).

Second, I do not think that an other-directed motive is sufficient to account for our intuitions about the respect in which moral behaviour transcends the self. Consider that, on van Niekerk's view, a moral agent is someone who ought to have the motive of acting for the sake of others, not her own self-interest. I presume that having the motive of acting for the sake of others includes having the belief that others are worth acting for without ultimate reference to one's self-interest. However, on van Niekerk's view, it is false that others are worth acting for without ultimate reference to one's self-interest. Hence, van Niekerk is implicitly proposing that a morally ideal agent is a person with a false belief about morality. For him, it appears, a morally ideal agent ought to believe that others are worth helping for their own sake, even though, according to him, in fact others are not worth helping for their own sake (since all basic reasons are constituted by self-development). In contrast, the view I am articulating does not suffer from this kind of incoherence. I maintain that there are other-regarding, relational basic reasons for action and that a morally good agent is one who acts in light of this fact.

If I am right that not all basic reasons for action are self-regarding, but if one is attracted to the idea that ubuntu involves a focus on the basic value of living a genuinely human life, then perhaps one ought to explore a theory that I did not discuss in "Toward an African Moral Theory." Instead of claiming, with autocentrism, that rightness is a function of developing oneself, maybe one ought to explore the view that it is instead a matter of developing selves in general. This view would still be perfectionist, deeming moral status at bottom to be constituted by the realization of valuable aspects of human nature, but it would not be eudaimonist, since the relevant locus of value would be not merely in one's own such nature, but, in its most impartial version, wherever such a nature may be found and developed. ${ }^{16}$

16 The most developed version of this moral theory that I am familiar with in Western ethical philosophy is Hurka 1993. 


\section{References}

Bujo, B (2001) Foundations of an African Ethic: Beyond the Universal Claims of Western Morality, McNeil, B, trans. (New York: Crossroad Publishing Company).

Horgan, T and Timmons, M (1990-91) "New Wave Moral Realism Meets Moral Twin Earth," Journal of Philosophical Research 16: 447-65.

Hurka, T (1993) Perfectionism (New York: Oxford University Press).

Khoza, R (2005) Let Africa Lead (Johannesburg: Vezubuntu Publishing Ltd).

Mbiti, J (1989) African Religions and Philosophy, $2^{\text {nd }}$ edn (Oxford: Heinemann Educational Books).

Metz, T (2007a) "Toward an African Moral Theory," The Journal of Political Philosophy 15: 321-41.

Metz, T (2007b) "New Developments in the Meaning of Life," Philosophy Compass 2: $196-217$.

Metz, T (2008) "God, Morality and the Meaning of Life," in Athanassoulis, N and Vice, S, eds. The Moral Life (New York: Palgrave Macmillan).

Metz, T "Developing an African Moral Theory: A New Theory of Human Rights," unpublished manuscript.

Metz, T "Ubuntu, Dignity and Liability to be Killed," unpublished manuscript.

Nkondo, M "Ubuntu as a Public Policy in South Africa: A Conceptual Framework," unpublished manuscript.

Rachels, J (1999) The Elements of Moral Philosophy (New York: McGraw Hill Publishers).

Tutu, D (1999) No Future Without Forgiveness (New York: Random House).

Van Niekerk, J "Ubuntu and Moral Value," unpublished PhD dissertation.

Wiredu, K (1992) "Moral Foundations of an African Culture," in Wiredu, K and Gyekye, K, eds., Person and Community: Ghanaian Philosophical Studies, Volume 1 (Washington, D.C.: Council for Research in Values and Philosophy).

Wiredu, K (1996) Cultural Universals and Particulars: An African Perspective (Bloomington: Indiana University Press). 
Copyright of South African Journal of Philosophy is the property of Philosophical Society of Southern Africa (PSSA) and its content may not be copied or emailed to multiple sites or posted to a listserv without the copyright holder's express written permission. However, users may print. download, or email articles for individual use. 